\title{
Mama con "piel de naranja”: Presentación atípica, reporte de un caso
}

\section{“Orange Peel” Breast: Atypical Presentation, Case Report}

\author{
Jorge Enrique Cervantes Coka1(1) \\ Valeria Espinosa ${ }^{1}$ Diana Montoya ${ }^{1}$ \\ ${ }^{1}$ Hospital General de Agudos I. Pirovano, Ciudad Autónoma de
Buenos Aires, Argentina
}

Rev Argent Radiol 2021;85:21-23.

Estimados editores,

El edema mamario denominado mama "piel de naranja" (MPN) se caracteriza por el aumento del volumen, del grosor de la piel y de la densidad del parénquima mamario. ${ }^{1}$ Debido a sus diversas etiologías, representa un reto diagnóstico. Esas etiologías pueden corresponder tanto a cáncer de mama inflamatorio como a otras causas sistémicas no malignas tales como: mastitis, traumatismo, obstrucción linfática, oclusión venosa subclavia, necrosis grasa, linfoma, leucemia, cambios postirradiación, esclerosis sistémica progresiva, enfermedades
Cinthia Soledad Alarcón ${ }^{1} \quad$ Luisa Gómez ${ }^{1}$

Address for correspondence Jorge Enrique Cervantes Coka, MD, Monroe 3555, Ciudad Autónoma de Buenos Aires, Argentina (e-mail: drcervantesc@hotmail.com).

granulomatosas, síndrome nefrótico, pénfigo y otras afecciones de la piel o insuficiencia cardíaca congestiva (ICC)., ${ }^{2,3}$

La MPN, dependiendo de su etiología, puede ser bilateral y, en menor medida, unilateral. En caso de ser bilateral, hay que sospechar de causas sistémicas, como ICC, síndrome de vena cava superior, entre otras. De no encontrarse la causa, o de presentarse en forma unilateral, se debe descartar la presencia de masa para la toma de biopsia y, en ausencia de masa, considerar origen inflamatorio, para posterior seguimiento hasta su resolución. La MPN unilateral puede estar asociada a

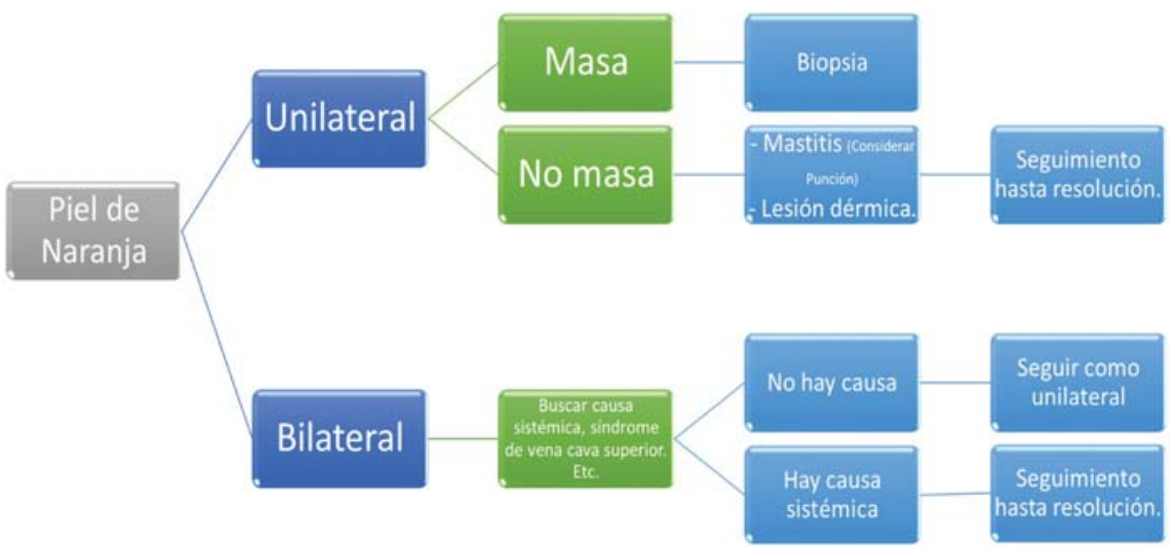

Figura 1 Algoritmo de manejo de la mama piel de naranja.

received

March 21, 2019

accepted

February 7, 2020

published online

April 22, 2020
DOI https://doi.org/

$10.1055 / \mathrm{s}-0040-1708464$

ISSN 1852-9992.

\footnotetext{
(C) 2020. Asociación Civil Sociedad Argentina de Radiología and Federacion Argentina de Asociaciones de Radiología, Diagnóstico por Imágenes y Terapia Radiante. All rights reserved.

This is an open access article published by Thieme under the terms of the Creative Commons Attribution-NonDerivative-NonCommercial-License, permitting copying and reproduction so long as the original work is given appropriate credit. Contents may not be used for commercial purposes, or adapted, remixed, transformed or built upon. (https://creativecommons.org/ licenses/by-nc-nd/4.0/)

Thieme Revinter Publicações Ltda., Rua do Matoso 170, Rio de Janeiro, RJ, CEP 20270-135, Brazil
} 

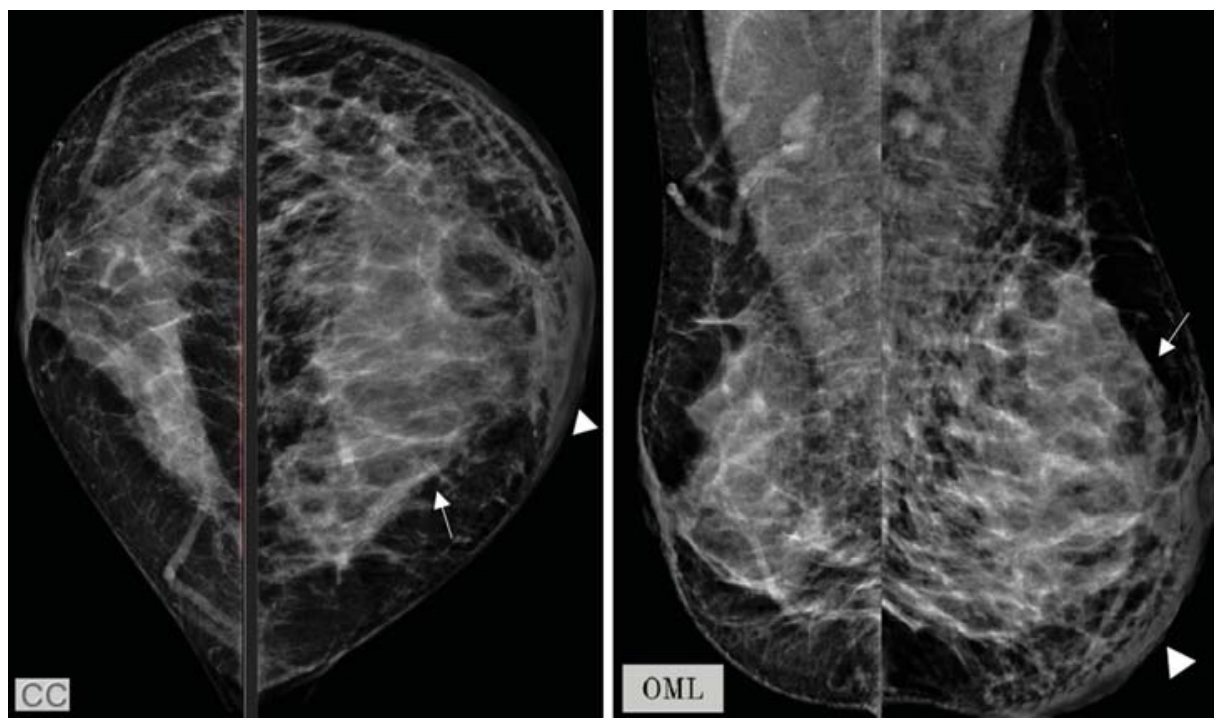

Figura 2 Mamografía bilateral incidencias CC y OML, Ilama la atención el aumento de la densidad y volumen de la mama izquierda (flecha), con engrosamiento del plano dérmico (punta de flecha).
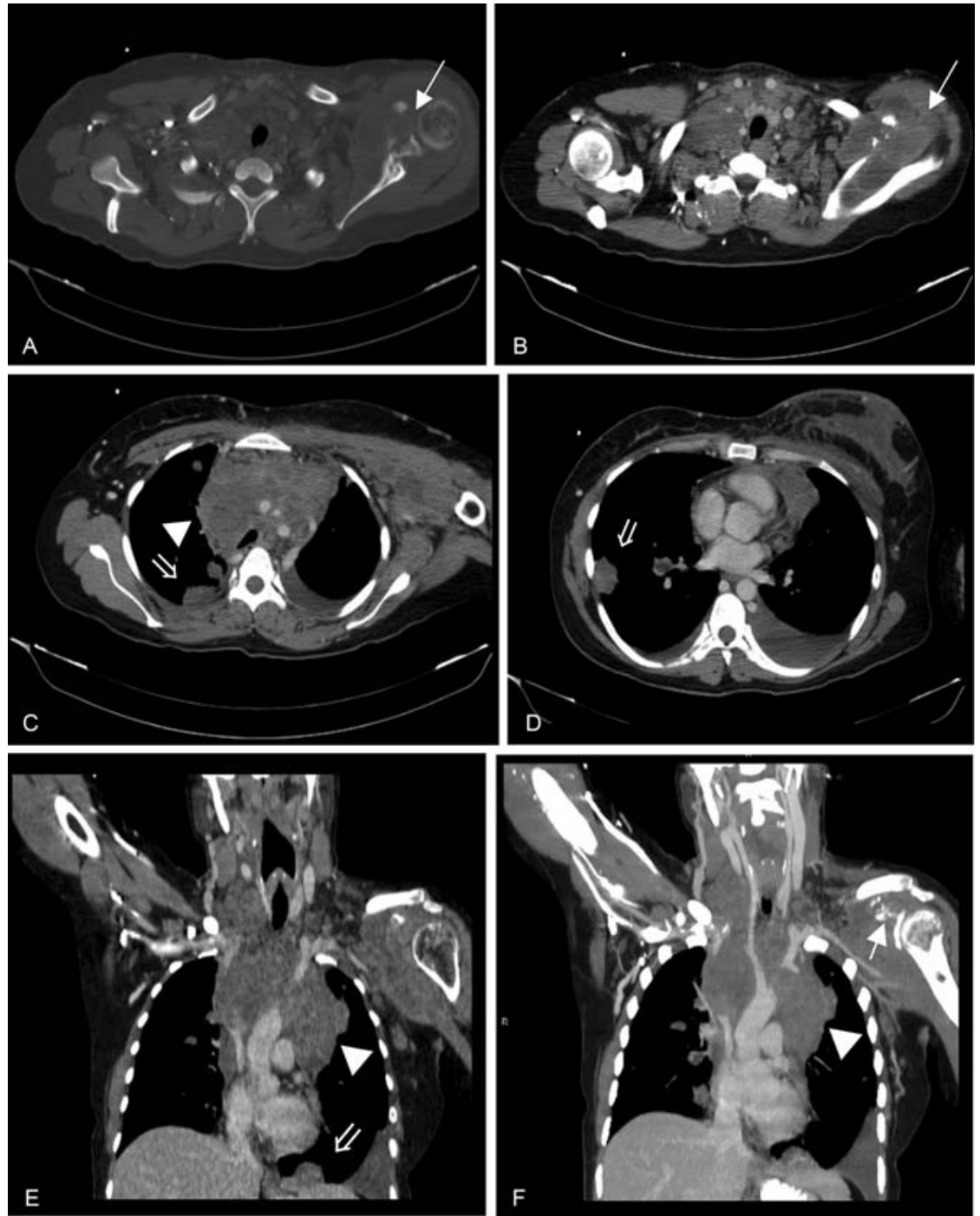

Figura 3 TC con contraste endovenoso. MPR vista axial (a, b, c, d) y vista coronal (e, f). Se observa lesión lítica en articulación gleno-humeral izquierda (flecha), conglomerado ganglionar mediastínico (punta de flecha), nódulos pulmonares bilaterales (flecha doble) y signos de trombosis y/o colapso extrínseco del tronco venoso braquiocefálico izquierdo (flecha en ángulo). 


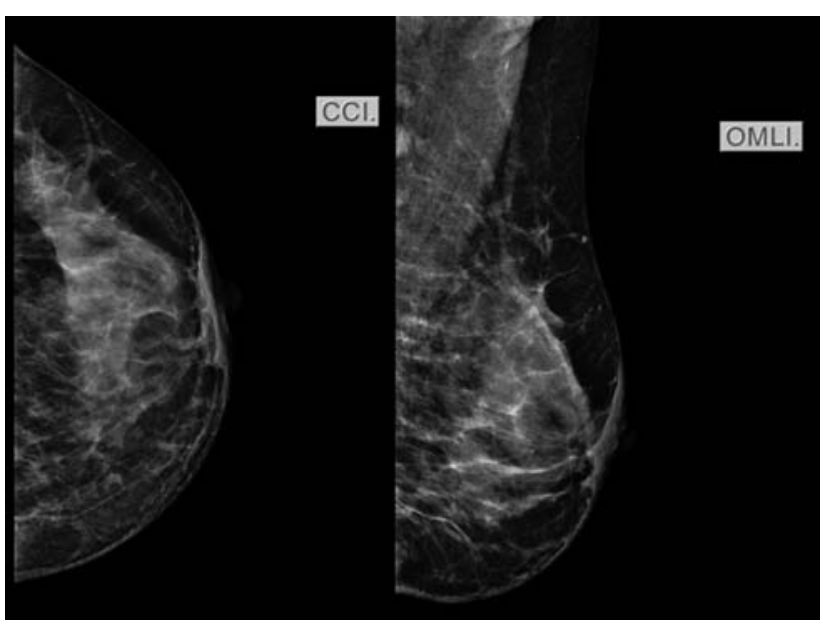

Figura 4 Mamografía de mama izquierda incidencia CC y OML. No se observan imágenes sugestivas de sospecha.

patología benigna, a patología maligna (cáncer inflamatorio) y, en menor frecuencia, a causa de origen no mamario (-Fig. 1). ${ }^{4}$

La mamografía y la ecografía, como métodos de imágenes, tienen como hallazgo en común el aumento del espesor del plano cutáneo, el cual debe superar los $3 \mathrm{~mm}$. En la mamografía, además, se visualiza aumento difuso de densidad y patrón reticular. En la ecografía se observa parénquima mamario heterogéneo con áreas hipoecoicas y con sombra acústica. ${ }^{5}$

Presentamos el caso de una paciente de 31 años, ex tabaquista (20 cigarrillos diarios entre los 13 y los 30 años), quien consultó al servicio de Guardia por presentar náuseas, vómitos, disfagia e inflamación de la mama izquierda de 48 horas de evolución, acompañado de dolor crónico en la articulación del hombro izquierdo. Al examen físico presentó mama izquierda aumentada de tamaño, con signos de flogosis y presencia de adenopatía supraclavicular única izquierda y axilares bilaterales múltiples. Se realizó mamografía bilateral en incidencia craneocaudal (CC) y oblicuo medio lateral (OML), en la que se observa aumento de la densidad y volumen de la mama izquierda, con engrosamiento de plano dérmico (-Fig. 2). Posteriormente, se realizó una tomografía computada (TC) con contraste oral y endovenoso (EV), con adquisiciones basales, en fase venosa (75 segundos) y fase excretora (10 minutos), en la que se visualizan conglomerados adenomegálicos que comprometen los compartimentos cervicales y mediastínicos, ocasionando compresión de las estructuras vasculares de la base del cuello, signos de trombosis y/o compresión extrínseca del tronco venoso braquiocefálico izquierdo y vena cava superior, múltiples nódulos pulmonares bilaterales con patrón en suelta de globos compatible con secundarismo, derrame pleural bilateral, lesión lítica expansiva a nivel de la cavidad glenoidea, cuerpo de la escápula izquierda y aumento difuso de la densidad y tamaño de la mama izquierda con engrosamiento cutáneo (-Fig. 3 ).

Debido a los hallazgos tomográficos, la paciente fue intervenida quirúrgicamente para toma de biopsia de adenopatía supraclavicular. Al momento de la operación, se administraron $100 \mathrm{mg}$ de hidrocortisona EV y $100 \mathrm{mg}$ EV cada 8 horas durante las primeras 24 horas postoperatorias.
En el postoperatorio mediato, la paciente fue programada para punción mamaria bajo guía ecográfica, por sospecha de carcinoma inflamatorio. Durante el abordaje ecográfico no se observaron imágenes dominantes sospechosas ni signos de inflamación mamaria, por lo que se suspendió el procedimiento. Se realizó mamografía de control de mama izquierda incidencias CCy OML, en la que se visualiza mama izquierda de características imagenológicas habituales (-Fig. 4).

Los hallazgos a nivel mamario caracterizado como MPN unilateral se interpretaron como síndrome de la vena cava superior unilateral ocasionado por la compresión ganglionar de las estructuras vasculares venosas del lado izquierdo, lo que se manifestó a través de la presencia de edema mamario unilateral asimétrico, que se resolvió tras la administración de corticoides. ${ }^{6}$

El resultado histopatológico de la biopsia obtenida del ganglio supraclavicular izquierdo resultó en un proceso linfoproliferativo de inmunofenotipo B, el cual produjo efecto de masa a nivel mediastínico, región latero cervical y presencia de conglomerados ganglionares, produciendo la sintomatología mamaria. ${ }^{7}$

Protección de personas y animales

Los autores declaran que para esta investigación no se han realizado experimentos en seres humanos ni en animales.

Confidencialidad de los datos

Los autores declaran que han seguido los protocolos de su centro de trabajo sobre la publicación de datos de pacientes.

Derecho a la privacidad y consentimiento informado Los autores declaran que en este artículo no aparecen datos de pacientes.

\section{Conflicto de Intereses}

Los autores del trabajo declaran no tener ningún conflicto de intereses.

\section{Bibliografía}

1 Cao MM, Hoyt AC, Bassett LW. Mammographic signs of systemic disease. Radiographics. 2011;31(04):1085-1100

2 Kwak JY, Kim EK, Chung SY, You JK, Oh KK, Lee YH. Unilateral breast edema: spectrum of etiologies and imaging appearances. Yonsei Med J. 2005;46(01):1-7

3 Kuerer HM, Wilson MW, Bowersox JC. Innominate vein stenosis mimicking locally advanced breast cancer in a dialysis patient. Breast J. 2001;7(02):128

4 Lorente Ramos R, Azpeitia Arman F, Balbin Carrero E, Rivera Garcia M, Casado Fariñas I, Cueva Perez E. Mama con "Piel de naranja", un signo de alerta y diferentes patologías. SERAM. 2014: S-0625

5 Crowe DJ, Helvie MA, Wilson TE. Breast infection. Mammographic and sonographic findings with clinical correlation. Invest Radiol. 1995;30(10):582-587

6 Clark CJ, Wechter D. Morphea of the breast-an uncommon cause of breast erythema. Am J Surg. 2010;200(01):173-176

7 Liberman L, Giess CS, Dershaw DD, Louie DC, Deutch BM. NonHodgkin lymphoma of the breast: imaging characteristics and correlation with histopathologic findings. Radiology. 1994;192 (01):157-160 